\title{
Endoscopic Treatment of Vesicoureteral Reflux: Changing Trends Over the Years
}

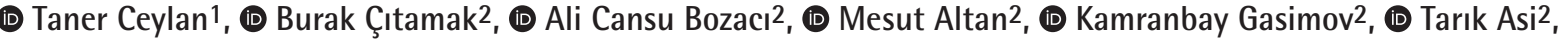 \\ (D) Hasan Serkan Doğan², (D) Serdar Tekgül2 \\ 1 University of Health Sciences Turkiye, Ankara Dr. Sami Ulus Maternity and Children's Health and Diseases Training and Research Hospital, Clinic \\ of Pediatric Urology, Ankara, Turkiye \\ 2Hacettepe University Faculty of Medicine, Department of Pediatric Urology, Ankara, Turkiye
}

\section{What's known on the subject? and What does the study add?}

Endoscopic subureteral injection (ESI) is an easy and minimally invasive procedure and may be an alternative to open surgery and continuous antibiotic prophylaxis by offering some advantages in patients with vesicoureteral reflux (VUR). In our study, we detected that the rate of patients with history of failed ESI, high grade reflux and renal scarring have increased significantly in our patient population over time. ESI is increasingly preferred with our increasing surgical experience over the years in patients who failed after the first ESI and especially in those with high grade VUR and appropriate ureter configuration on cystoscopy.

\section{Abstract}

Objective: To investigate factors affecting the success rate of endoscopic subureteral injection (ESI) in patients with vesicoureteral reflux (VUR) and to evaluate the changes in years.

Materials and Methods: A total of 439 patients with primary VUR who underwent ESI were included. We used dextranomer hyaluronic acid copolymer (Dx-HA) as bulking agent. Statistical analyzes were performed by SPSS 20.0 programme.

Results: Overall patient-based and renal unit-based success rates of ESI were $75.6 \%$ and $78.2 \%$, respectively. Operational age of 82 months and lower grades of VUR were found to be the factors increasing success rate ( $p=0.023, p=0.005$ ). Success rates were as $83.6 \%$, $77.9 \%$ and $64.5 \%$ for grades of reflux $1-2,3$ and $4-5$, respectively $(p=0.002)$. When patients were seperated into four equal chronological groups, we observed that the ratio of patients who had previous failed ESI, high-grade reflux and renal scarring and volume of injected material has increased over the years.

Conclusion: ESI has higher success rates in older children and lower grades (grades 1-3) of VUR. It is performed also in high-grade patients with acceptable success rates which tended to increase over the years.

Keywords: Vesicoureteral reflux, endoscopic subureteral injection, STING procedure, dextranomer hyaluronic acid co-polymer

\section{Introduction}

Vesicoureteral reflux (VUR) is one of the most common urological abnormalities in children with an incidence of approximately 1\% (1). Appropriate management, either via conservative or surgical means, is crucial to prevent complications of VUR, such as hypertension, pyelonephritis, renal scarring and renal failure $(2,3)$. Treatment options include close observation, continuous antibiotic prophylaxis (CAP), endoscopic subureteric injection
(ESI) and open/laparoscopic/robotic ureteric reimplantation. Some indications for surgical intervention are breakthrough urinary tract infection (BTI) despite antibiotic prophylaxis, progression (reflux grade, symptoms and parenchymal damage) and parental preference (2)

$\mathrm{ESI}$, an easy and minimally invasive procedure, may be an alternative to open surgery. It offers excellent advantages over other methods, such as low morbidity, short post-operative recovery time and low cost (3).

Correspondence: Taner Ceylan MD, University of Health Sciences Turkiye, Ankara Dr. Sami Ulus Maternity and Children's Health and Diseases Training and Research Hospital, Clinic of Pediatric Urology, Ankara, Turkiye

Phone: +90 5529385938 E-mail: ceylanta73@gmail.com ORCID-ID: orcid.org/0000-0003-4044-1778

Received: 02.01.2021 Accepted: 21.02 .2021

Cite this article as: Ceylan T, Çıtamak B, Bozacı AC, Altan M, Gasimov K, Asi T, Doğan HS, Tekgül S. Endoscopic Treatment of Vesicoureteral Reflux: Changing Trends Over the Years. J Urol Surg 2021;8(2):123-129.

๑Copyright 2021 by the Association of Urological Surgery / Journal of Urological Surgery published by Galenos Publishing House. 
We hypothesised that ESI treatment of VUR is effective even in high-grade cases. Thus, in this study, we aimed to investigate the factors affecting the success rate of ESI in patients with VUR and evaluate changes in our patient profiles and surgical outcomes over time.

\section{Materials and Methods}

Data from a total of 439 patients younger than 18 years old who underwent ESI between 2000 and 2020 were retrospectively collected. Informed consent was obtained from the patients' parents prior to the operation. The higher grade in patients with bilateral VUR was recorded as "the reflux grade". Reflux grades were classified as "low" for grades 1-2 reflux, "moderate" for grade 3 reflux and "high" for grades 4-5 reflux. Forty-four patients with incomplete data, neurogenic bladder, ureterocele and duplex system were excluded from the study.

Lower urinary tract dysfunction (LUTD) is defined as the presence of lower urinary tract symptoms in children older than 5 years; these symptoms may include urgency, incontinence, poor voiding flow rate, intermittent voiding and pollacuria, all of which may be detected by questionnaires and/or urodynamic studies. Prior to any surgery, behavioural arrangements (urotherapy) and/or medications were first recommended and administered to all patients with LUTD.

In our study, the indications for surgery were recurrent or symptomatic urinary tract infection (UTI) despite CAP, increasing reflux grade and renal scarring and, sometimes, parental preference. All patients underwent the classical STING technique under the supervision of two paediatric urology board-certified clinicians (H.S.D. and S.T.). Positioned instillation of contrast cystography (PIC-C) on the contralateral ureter was performed in some patients with unilateral reflux in case an incompetent appearance and presence or suspicion of scarring on DMSA were noted. ESI of the contralateral ureter was performed if reflux was detected by PIC-C. We used dextranomer-hyaluronic acid co-polymer (Dx/HA) as the injection material. Ureteral orifices with a golf-hole appearance were not injected. Bladders were drained for 24 hours with a Foley catheter, and patients were hospitalised for approximately 1 day (range, 0-2 days) after surgery.

We performed early ultrasonography 1 month after operation, every 3 months in year 1, every 6 months in year 2 and then every year thereafter up to year 5 . All patients were given antibiotic prophylaxis until follow-up voiding cystourethrography (VCUG), which was performed once between 3 and 6 months after operation. Our definition of success was based on the patient, not the renoureteral unit; thus, a procedure was considered "successful" if no reflux in any side of the organ was observed during follow-up VCUG.
We constructed four chronological groups including nearly equal numbers of patients to evaluate changes in patient characteristics and treatment outcomes as follows: group 1 ( $n=109$; those operated on between 2000 and 2009), group 2 $(n=110$; those operated on between 2010 and 2012), group 3 ( $n=110$; those operated on between 2013 and 2016) and group 4 ( $n=110$; those operated on between 2016 and 2020).

\section{Statistical Analysis}

Statistical Package for the Social Sciences version 20 software (SPSS Inc., Chicago, IL, USA) was used for statistical analyses. The Mann-Whitney U, Kruskal-Wallis, chi-squared and t-tests were used where appropriate, and logistic regression analysis was used for multivariate analysis. A $p$-value of $<0.05$ was considered to be significant. The area under the curve (AUC) calculated from the receiver operating characteristic (ROC) curve was used to assess the predictive ability of age.

\section{Results}

The male-to-female ratio was 108/331 (24.6\%/75.4\%). The mean age at diagnosis and mean operation age were as $64.9 \pm 50.5$ and $82.4 \pm 51.9$ months, respectively. The mean follow-up period was $17.3 \pm 24.9$ months. Unilateral VUR was present in 244 patients (55.6\%), whilst bilateral VUR was noted in 195 (44.4\%). The VUR grade of 116 patients was low, that of 199 patients was moderate and that of 124 patients was high $(26.5 \%, 45.3 \%$ and $28.2 \%$, respectively). Of the patients with bilateral reflux $(n=195), 131$ had low-grade VUR on both sides (67.2\%), 33 had high-grade VUR on both sides (16.9\%) and 31 had low-grade VUR on one side and high-grade VUR on the other (15.9\%). Contralateral VUR was detected intraoperatively by PIC-C in 46 of 244 unilateral reflux patients. Therefore, ESI was performed unilaterally and bilaterally in 198 and 241 patients, respectively. Our overall radiological patient-based success rate was 75.6\%. Success rates according to pre-operative VUR grades $1-2,3$ and $4-5$ were $83.6 \%, 77.9 \%$ and $64.5 \%$, respectively ( $p=0.002$ in univariate analyses; $p=0.005$ in multivariate analyses). We detected radiological patient-based success rates in patients with bilateral low, low/high and bilateral high grades as $77.1 \%$, $71 \%$ and $63.6 \%$, respectively; differences noted amongst groups were not statistically significant $(p=0.268)$. Of 151 patients whose unilateral reflux completely disappeared on control VCUG, two had post-operative contralateral reflux (1.3\%).

The mean age of patients with post-operative success was older. When the effect of age on overall success rate was examined, 82 months appeared to be the cut-off with the best predictive value ( $p=0.002,51.6 \%$ sensitivity on the ROC curve, $A U C=0.586$ with $66.3 \%$ specificity). Success rates of $70.7 \%$ and 
$83.5 \%$ were obtained in patients younger and older than 82 months, respectively, and the difference noted between groups was significant $(p=0.002$ in univariate analyses; $p=0.023$ in multivariate analyses).

We obtained the pre-operative data of renal scarring status in 407 patients $(M / F$ ratio=100/307) and renal scarring was detected in 221 individuals (54.3\%). The rates of renal scarring in patients with high- and low-grade reflux were $71.8 \%$ (84/117) and $47.2 \%(137 / 290)$, respectively $(p<0.001)$. The presence of renal scarring was not affected by gender (male: $59 \%$ vs female: $52.8 \%, p=0.277$ ) or LUTD status (with LUTD: $59.5 \%$ vs without LUTD: $60.3 \%, p=0.900$ ).

We also obtained data on the volume of injected material 481 $\mathrm{RU}$ (307 patients), and the mean injected volume was $1.05 \pm 0.43$ $\mathrm{mL}$ (range, $0.3-2 \mathrm{~mL}$ ). Analysis of overall groups revealed no statistical difference in injected volume or its effect on outcomes. The mean volumes for patients with successful and failed operations were 1.06 and $1.01 \mathrm{cc}$, respectively $(p=0.109$, Mann-Whitney U test). However, when we analysed the data by grade, we found that injected volumes were higher in groups with low (1.03 mL vs $0.83 \mathrm{~mL}, \mathrm{p}=0.019)$ and high $(1.19 \mathrm{~mL}$ vs $1.02 \mathrm{~mL}, \mathrm{p}=0.045)$ grades than in that with a moderate grate. The difference observed was not significant in moderate-grade patients $(1.01 \mathrm{~mL}$ vs $1.05 \mathrm{~mL}, \mathrm{p}=0.721)$. We learned that $0.75 \mathrm{~mL}$ is the best possible cut-off point ( $82 \%$ sensitivity, $31 \%$ specificity, $\mathrm{AUC}=0.545, p=0.148$ ). Higher volumes were associated with higher success rates (Table 1). Chronological evaluation showed that the volume of the injected material increased with time (Table 2).

Multivariate analysis revealed that age less than 82 months, high reflux grade and volume of the injected material of less than $0.75 \mathrm{~mL}$ were associated with failure.

We examined the four chronological groups and found that the number of patients with a history of failed endoscopic procedure, high-grade reflux, renal scarring and volume of injected material increased significantly over time (Table 2).

An indication for intervention was pre-operative symptomatic UTI, which was detected in $39 \%$ of the patients and significantly decreased to $18.5 \%$ within the post-operative follow-up period (McNemar test, $p<0.001$ ). Univariate and multivariate analyses revealed that post-operative UTI occurred significantly more frequently in females than in males and in those with preoperative BTI than in those without ( $p=0.001, p=0.049$ and $p<0.001$, respectively). Post-operative success and UTI rates according to various factors are shown in Table 1.

\begin{tabular}{|c|c|c|c|c|c|c|c|}
\hline & & $\begin{array}{l}\text { Success } \\
\%(\mathrm{n})\end{array}$ & $\mathrm{p}^{*}$ & $\mathbf{p}^{* *}$ & $\begin{array}{l}\text { Post-op. UTI } \\
\% \text { (n) }\end{array}$ & $\mathrm{p}^{*}$ & $\mathbf{p}^{* *}$ \\
\hline \multirow[b]{2}{*}{ Gender } & Male & $73.1(79)$ & \multirow{2}{*}{0.490} & & $7.4(8)$ & \multirow{2}{*}{$0.001^{*}$} & \multirow{2}{*}{$0.006^{*}$} \\
\hline & Female & 76.4 (253) & & & $22.1(73)$ & & \\
\hline \multirow{2}{*}{$\begin{array}{l}\text { Age } \\
\text { (month) }\end{array}$} & $<82$ & 70.7 (152) & \multirow{2}{*}{$0.002^{*}$} & \multirow{2}{*}{$0.023^{* *}$} & $18.2(41)$ & \multirow{2}{*}{0.899} & \\
\hline & $\geq 82$ & $83.5(162)$ & & & $18.7(40)$ & & \\
\hline \multirow{2}{*}{$\begin{array}{l}\text { Side of } \\
\text { VUR }\end{array}$} & Unilateral & 77.0 (188) & \multirow{2}{*}{0.437} & & $19.7(48)$ & \multirow{2}{*}{0.461} & \\
\hline & Bilateral & $73.8(144)$ & & & $16.9(33)$ & & \\
\hline \multirow{3}{*}{ Preop. grade of VUR } & $1-2$ & $83.6(97)$ & \multirow{3}{*}{$0.002^{*}$} & \multirow{3}{*}{$0.005^{* *}$} & $18.1(21)$ & \multirow{3}{*}{0.501} & \\
\hline & 3 & 77.9 (155) & & & $16.6(33)$ & & \\
\hline & $4-5$ & $64.5(80)$ & & & $21.8(27)$ & & \\
\hline \multirow{2}{*}{$\begin{array}{l}\text { History of LUTD } \\
(>5 \text { y.o })\end{array}$} & No & $81.2(112)$ & \multirow{2}{*}{0.342} & & $14.5(20)$ & \multirow{2}{*}{0.105} & \\
\hline & Yes & 76.5 (104) & & & $22.1(30)$ & & \\
\hline \multirow{2}{*}{ Preop. BTI } & No & 77 (188) & \multirow{2}{*}{0.368} & & $13.5(33)$ & \multirow{2}{*}{$<0.001^{*}$} & \multirow{2}{*}{$<0.001^{* *}$} \\
\hline & Yes & $73.1(114)$ & & & $28.8(45)$ & & \\
\hline \multirow{2}{*}{ History of failed STING } & No & $77(264)$ & \multirow{2}{*}{0.254} & & $17.8(61)$ & \multirow{2}{*}{0.590} & \\
\hline & Yes & $71.3(67)$ & & & $20.2(19)$ & & \\
\hline \multirow{2}{*}{ Renal scar } & No & $75.8(141)$ & \multirow{2}{*}{0.995} & & $18.8(35)$ & \multirow{2}{*}{0.760} & \\
\hline & Yes & 75.6 (167) & & & $17.6(39)$ & & \\
\hline \multirow{2}{*}{ Injected volume (mL) } & $\leq 0.75$ & 64.9 & \multirow{2}{*}{0.004} & \multirow{2}{*}{$0.014^{* *}$} & 18.6 & \multirow{2}{*}{0.846} & \\
\hline & $>0.75$ & 78.9 & & & 17.7 & & \\
\hline
\end{tabular}


Table 2. Pre- and post-operative features of patients in the different chronological groups

\begin{tabular}{|c|c|c|c|c|c|}
\hline Features & $\begin{array}{l}\text { Group } 1 \\
2000-2009\end{array}$ & $\begin{array}{l}\text { Group } 2 \\
\text { 2010-2012 }\end{array}$ & $\begin{array}{l}\text { Group } 3 \\
2013-2016\end{array}$ & $\begin{array}{l}\text { Group } 4 \\
2016-2020\end{array}$ & $\mathbf{p}$ \\
\hline No. of patients & 109 & 110 & 110 & 110 & - \\
\hline Gender (F/M) & $91 / 18$ & $79 / 31$ & $82 / 28$ & $79 / 31$ & 0.145 \\
\hline Mean age at diagnosis (months) & 62.99 & 67.07 & 65.03 & 64.22 & 0.967 \\
\hline Mean operation age (months) & 80.32 & 80.38 & 79.74 & 82.91 & 0.920 \\
\hline Side (unilateral/bilateral) & $61 / 48$ & $61 / 49$ & $62 / 48$ & $60 / 50$ & 0.994 \\
\hline LUTD +/- (patients > 5 y.o) & $35 / 37(72)$ & $32 / 36(68)$ & $36 / 34(70)$ & $37 / 32$ (69) & 0.872 \\
\hline History of failed STING & $15.6 \%$ & $16.4 \%$ & $20.9 \%$ & $32.7 \%$ & 0.007 \\
\hline VUR grades 4 and 5 & $14.7 \%$ & $23.6 \%$ & $32.7 \%$ & $41.8 \%$ & $<0.001$ \\
\hline Success rate in grades 4 and 5 & $62.5 \%$ & $65.4 \%$ & $63.9 \%$ & $65.2 \%$ & 0.997 \\
\hline Overall success rate & $73.4 \%$ & $70.9 \%$ & $77.3 \%$ & $80.9 \%$ & 0.328 \\
\hline Renal scar & $45.9 \%$ & $47.6 \%$ & $58.3 \%$ & $65.3 \%$ & 0.017 \\
\hline Injected volume (cc) & 0.84 & 0.90 & 1.16 & 1.21 & $<0.001$ \\
\hline
\end{tabular}

We detected post-operative ureteral obstruction in two patients (0.4\%) 6 and 9 months post operation, and both patients underwent open ureteral reimplantation. None of the patients revealed signs of obstructive reflux (e.g. breaking signs or sustained contrast material in the ureter after bladder emptying) during pre-operative VCUG. Patient 1 was a 4-yearold boy who underwent ESI with $1 \mathrm{~mL}$ of material for unilateral left-sided grade 4 VUR. Post-operative VCUG was normal on the third month. He interestingly developed bilateral worsening hydroureteronephrosis on the ninth month post operation. We suspected overlooked LUTD, which we evaluated by questioning and videourodynamic study. However, no abnormal functions were found. Thus, we performed bilateral open reimplantation to correct the issue. Patient 2 was an 18-month-old girl with unilateral left-sided grade 4 VUR, which was treated by $1 \mathrm{~mL}$ of material. We detected worsening hydroureteronephrosis 6 months post operation with symptomatic pain prior to the control VCUG. We performed cystoscopy under anaesthesia, which revealed no reflux in cystography but obstruction in retrograde pyelography; thus, we placed a Double J stent. However, the patient's issue did not resolve during followup, and unilateral open reimplantation was performed. No difficulty was encountered during ureteral dissection in these 2 patients, and neither of showed obstructive refluxing ureter preoperatively.

\section{Discussion}

One of the main objectives of this study is to evaluate the factors affecting the success of ESI in children. The overall success rate of ESI with Dx/HA has been reported to be between $68 \%$ and $92 \%$, which is comparable with open surgery $(4,5)$. In our study, the overall patient-based success rate of ESI was $75.6 \%$, which is comparable with the rates reported in the literature. In previous studies, pre-operative reflux grade, renal scarring, age, gender, anatomical anomalies, injection technique, injection volume, surgical experience and accompanying LUTD were reported as factors affecting the success rate of ESI $(5,6)$. In our study, the effects of age and VUR grade on the success rate were found to be statistically significant.

In a meta-analysis, Elder et al. (5) reviewed 63 studies including 5,527 patients and reported that the success rate of ESI decreased as the VUR grade increased and that the success rates of single-session ESI were as high as 78.5\%, 72\%, 63\% and $51 \%$ for VUR grades 1-2, 3, 4 and 5, respectively. In our study, the success rates of the STING procedure in patients with VUR grades $1-2,3$ and $4-5$ were calculated as $83.6 \%, 77.9 \%$ and $64.5 \%$, respectively ( $p=0.005)$. The relatively high success rate in high-grade cases in our series may be attributed to the fact that we did not perform ESI in orifices with a clear golf-hole appearance. Therefore, we also selected the patients according to their anatomic deficiency at the time of cystoscopy.

The effect of LUTD in children $>5$ years old on the success of ESI with Dx/HA remains unclear. Capozza et al. (7) detected concomitant LUTD in nearly all patients who had failure of ESI and displacement of the Dx/HA mound and supposed that high voiding pressures secondary to LUTD may have caused the observed displacement. Lavelle et al. (8) reported that the success of ESI in patients with LUTD is not significantly different compared with those without and that ESI with Dx/HA is not contraindicated in these patients. Of the 274 patients older than 5 years of age in our study, 136 (49.6\%) had LUTD. The success rates of ESI were calculated to be $76.5 \%$ and $81.2 \%$ in patients with and without LUTD, respectively; however, the difference between groups was not statistically significant $(p=0.342)$. 
Our main aim is to investigate LUTD in patients with VUR, especially those who are $>5$ years old, by using questionnaires and urodynamic studies, if necessary. We believe that that insignificant effect of LUTD on the success rate of ESI in our study may be due to our provision of standard urotherapy and/ or medical treatment to all patients with LUTD prior to surgery and excluding the patients with neurogenic bladder from the study. American Urological Association guidelines recommend that concomitant LUTD should be investigated and treated in all patients with VUR regardless whether surgery is planned (2). In this sense, age could be a factor, as shown by a previous study (9). In our study, we found the success rates of ESI in patients younger and older than 82 months to be $70.7 \%$ and $83.5 \%$, respectively $(p=0.023)$. We feel that relatively higher voiding pressures and unstable bladder dynamics in younger children who are not fully toilet-trained may have resulted in lower success rates.

The presence of renal scarring is an indication for intervention, and our patients with high-grade VUR had significantly higher rates of renal scarring compared with those with low-grade VUR ( $71.8 \%$ vs $47.2 \%, p<0.001$ ), as expected (10). Pre-operative renal scarring status did not significantly affect our post-operative success and UTI rates ( $p=0.995$ and $p=0.760$, respectively).

An important aim of ESI in VUR is to prevent episodes of UTI. However, post-operative UTI may also be observed after successful surgery; this issue has been reported to occur more frequently in patients with persistent reflux, LUTD, history of BTI and female gender (4). In our series, the post-operative UTI rate was found to be $18.5 \%$, and UTI was detected more frequently in females and patients with pre-operative BTI.

We detected contralateral reflux by control VCUG in two of 151 patients whose unilateral reflux completely disappeared $(1.3 \%)$. The rate of contralateral reflux is reported to be between $7.9 \%$ and $12.5 \%$ in the literature $(8,10,11)$. Our very low rate of contralateral reflux in unilateral ESI patients may be due to our use of intra-operative PIC-C for the contralateral side. We performed ESI in the same session in case contralateral reflux was detected. This approach seems to decrease the rate of post-operative contralateral reflux. We were also aware of the extremely low chance of detecting VUR by conventional postoperative VCUG on the contralateral side detected by PIC-C. This can only be evaluated by means of clinical observation as postoperative febrile UTI with symptoms of pain on the relevant ureteral unit.

The effect of the volume of injected material on the surgical outcome is controversial $(3,12)$. Although subgroup analysis revealed that higher material volumes are associated with success in low- and high-grade reflux cases, evaluation of overall groups did not yield a difference between successful and failed cases. This insignificance may be due to the fact that $45 \%$ of the sample population comprised cases with moderate-grade reflux. Our finding of an increase in injection volume over the years is similar to that reported in a previous study (13). This result can be attributed to increases in the number of the patients with high-grade reflux during the time period. The frequent use of PIC-C and application of injection to the contralateral side in some patients may also explain this interesting result.

The injection technique may be another point of interest in the interpretation of surgical outcomes. The hydrodistention implantation technique (HIT) and double HIT methods were popularised by Kirsch and Arlen (14) and showed higher success rates than the STING method; thus, these methods gained wide acceptance amongst clinicians (4). We also perform these modified techniques in our daily practice, especially in highgrade reflux cases. However, we do not have a sufficient number of cases with adequate follow-up to compare these techniques with the standard STING method. Therefore, we are unable to comment on this topic at this time.

Another main objective of the present study is to observe changes in patient characteristics and surgical outcomes. Amongst the four chronological groups, we determined that ESI had become increasingly preferred in the last 10 years. We believe that this finding may be attributed to the increased availability of and developments in ESI procedures for VUR over the years. We also found that the rate of patients with a history of failed ESI, highgrade reflux and renal scarring increased significantly over time. Although statistically insignificant, our overall success rate slightly increased over time despite the increased number of patients with high reflux grades. This finding may be due to the frequent preference of ESI for patients with high-grade VUR if the ureter configuration seems normal and the submucosal tunnel is found to be relatively long during cystoscopy. In other words, when the status of the ureter orifice and submucosal tunnel in cystoscopy is considered rather than the pre-operative degree of reflux, higher success rates can be obtained through ESI even in patients with high-grade reflux.

We believe that the increase in history of failed ESI over the time may be attributed to our institution becoming a referral centre; our surgical knowledge and experience in dealing with patients with a history of failed ESI, especially those with the appropriate ureter configuration, has led to ESI becoming the preferred treatment of choice. Indeed, we observed that a history of previous failed ESI history did not affect our surgical outcomes.

In the literature, the most significant complication after ESI was reported to be ureterovesical (UV) obstruction (15). If recognised in the early post-operative period, most obstructions resolve with close follow-up or after placement of a temporary ureteral 
stent. However, ureteral obstruction can develop without any symptoms. Therefore, post-operative follow-up for 3-5 years is recommended. However, according to the recent systematic review of Friedmacher and Puri (16), the incidence of ureteral obstruction is less than $1 \%$ and the issue can develop regardless of the material type, volume of injected material, injection technique or ESI history. We performed early ultrasonography 1 month post operation, every 3 months for year 1, every 6 months for year 2 and every year thereafter up to year 5 . Here we experienced $2(0.4 \%)$ cases of delayed UV obstruction within the first year post operation, which was addressed by open reimplantation.

Although several studies on the efficacy of ESI in children are available, the present study is unique in that it includes a large number of patients and a long follow-up period. These features provide excellent opportunities to observe changes in patient characteristics and analyse the factors affecting treatment outcomes.

\section{Study Limitations}

This study presents some limitations that may affect the generalisability of the results. First, this study is retrospective in nature, and we were unable to obtain data on the injected volumes of Dx/HA and pre-operative renal scarring for each patient. Moreover, post-operative USG in the follow-up period was investigated only if ureterohydronephrosis was present, and the height of the mound was not measured in all patients. Finally, routine annual VCUG was not performed for delayed recurrences. However, delayed VCUG was performed in patients with symptomatic infection or sustained hydroureteronephrosis.

\section{Conclusion}

The surgical outcomes of ESI are better in older children and those with low-grade VUR. Post-operative UTI develops more frequently in girls than boys and in patients with pre-operative BTI than in those without. The presence of LUTD does not change the outcome if properly treated before ESI. Given the extensive knowledge obtained over years of experience, endoscopic methods are generally preferred even in children with highgrade VUR and a history of failed STING.

\section{Ethics}

Ethics Committee Approval: Data from a total of 439 patients younger than 18 years old who underwent ESI between 2000 and 2020 were retrospectively collected.

Informed Consent: Informed consent was obtained from the patients' parents prior to the operation.
Peer-review: Externally and internally peer-reviewed.

\section{Authorship Contributions}

Surgical and Medical Practices: H.S.D., S.T., Concept: T.C., B.Ç., H.S.D., Design: T.C., H.S.D., S.T., Data Collection or Processing: T.C., A.C.B., M.A., K.G., T.A. Analysis or Interpretation: T.C., A.C.B., M.A., H.S.D., Literature Search: T.C., B.Ç., Writing: T.C., H.S.D.

Conflict of Interest: No conflict of interest was declared by the authors.

Financial Disclosure: The authors declare that they have no relevant financial.

\section{References}

1. Lebowitz RL. The detection and characterization of vesicoureteral reflux in the child. J Urol 1992;148:1640-1642.

2. Peters CA, Skoog SJ, Arant BS Jr, Copp HL, Elder JS, Hudson RG, Khoury AE Lorenzo AJ, Pohl HG, Shapiro E, Snodgrass WT, Diaz M. Summary of the AUA Guideline on Management of Primary Vesicoureteral Reflux in Children. J Urol 2010;184:1134-1144.

3. Routh JC, Inman BA, Reinberg Y. Dextranomer/hyaluronic acid for pediatric vesicoureteral reflux: systematic review. Pediatrics 2010;125:1010-1019.

4. Kirsch AJ, Arlen AM, Lackgren G. Current trends in dextranomer hyaluronic acid copolymer (Deflux) injection technique for endoscopic treatment of vesicoureteral reflux. Urology 2014;84:462-468.

5. Elder JS, Diaz M, Caldamone AA, Cendron M, Greenfield S, Hurwitz R, Kirsch A, Koyle MA, Pope J, Shapiro E. Endoscopic therapy for vesicoureteral reflux: a meta-analysis. I. Reflux resolution and urinary tract infection. J Urol 2006;175:716-722.

6. Routh JC, Reinberg Y. Predicting success in the endoscopic management of pediatric vesicoureteral reflux. Urology 2010;76:195-198.

7. Capozza N, Lais A, Matarazzo E, Nappo S, Patricolo M, Caione P. Influence of voiding dysfunction on the outcome of endoscopic treatment for vesicoureteral reflux. J Urol 2002;168:1695-1698.

8. Lavelle MT, Conlin MJ, Skoog SJ. Subureteral injection of Deflux for correction of reflux: analysis of factors predicting success. Urology 2005;65:564-567.

9. Dogan HS, Altan M, Citamak B, Bozaci AC, Koni A, Tekgul S. Factors affecting the success of endoscopic treatment of vesicoureteral reflux and comparison of two dextranomer based bulking agents: does bulking substance matter? J Pediatr Urol 2015;11:90.

10. Mattoo TK, Chesney RW, Greenfield SP, Hoberman A, Keren R, Mathews R, Gravens-Mueller L, Ivanova A, Carpenter MA, Moxey-Mims M, Majd M, Ziessman HA; RIVUR Trial Investigators. Renal Scarring in the Randomized Intervention for Children with Vesicoureteral Reflux (RIVUR) Trial. Clin J Am Soc Nephrol 2016;11:54-61.

11. Guerra LA, Khanna P, Levasseur M, Pike JG, Leonard MP. Endoscopic treatment of vesicoureteric reflux with Deflux: a Canadian experience. Can Urol Assoc J 2007;1:41-45.

12. Dave $S$, Bägli DJ. A review of the effect of injected dextranomer/hyaluronic Acid copolymer volume on reflux correction following endoscopic injection. Adv Urol 2008;2008:579370.

13. Sorensen MD, Koyle MA, Cowan CA, Zamilpa I, Shnorhavorian M, Lendvay TS. Injection volumes of dextranomer/hyaluronic acid are increasing in the endoscopic management of vesicoureteral reflux. Pediatr Surg Int 2010;26:509-513. 
14. Kirsch AJ, Arlen AM. Evaluation of new Deflux administration techniques: intraureteric HIT and Double HIT for the endoscopic correction of vesicoureteral reflux. Expert Rev Med Devices 2014;11:439-446.

15. Christen $S$, Mendoza M, Gobet R, Bode P, Weber D. Late ureteral obstruction after injection of dextranomer/hyaluronic acid copolymer. Urology 2014;83:920-922.
16. Friedmacher F, Puri P. Ureteral Obstruction After Endoscopic Treatment of Vesicoureteral Reflux: Does the Type of Injected Bulking Agent Matter? Curr Urol Rep 2019;20:49. 